\title{
PROCESS CAPABILITY STUDY IN SERIAL PRODUCTION OF AUTOMOTIVE PARTS
}

\begin{abstract}
In the manufacturing processes there has long been demanded the increasing requirements for high quality products especially in automotive industry. In order to assure such as high quality standards the production process and further the product quality the organization must have implemented tools enabling to monitor and have the ambition to dwindle variability. The low variability provides better process predictability, standardized quality level, less occurrence of non-conformities; the products reveal better longevity and finally the satisfied customers. The long lasting endeavor for widely recognized parameters with ambition to determine current status of quality parameter has brought indicators in a form of $\mathrm{C}_{\mathrm{p}}$ and $\mathrm{C}_{\mathrm{pk}}$ into the business. The article deals with theoretical approach of previously mentioned indicators, an observation of critical to quality parameters in production process, definition of resulting problems, and finally the proposal of improvement including its verification.
\end{abstract}

Keywords: capability, quality assurance, quality tools

\section{Introduction}

It certainly would be very interesting to have some insight into the future. When manufacturing a product or providing a service, decision makers would like to know if a product or service provided in the future is capable of meeting customer specifications and expectations. The tools replacing a "crystal ball" are Control charts enabling insight into the capability of a manufacturing process and what future production might be like. The contemporary quality level of key processes with successful worldwide known organizations in terms of sigma indicator lies between 34 sigma. Such a quality level is responsible for at least 20000 wrongly prepared remedies per year, 96 air flight accidents for 100000 flights, harmful drinking water for at least one hour a day, and interrupted phone services or television broadcast for 10 minutes a day (GINN D., STREIBEL B., VITAL E.V. 2007). Generally spoken quality can be explain as the characteristics of a product or service which bear on its ability to satisfy stated or implied needs and a product or service free of deficiencies (SUMMERS D. 1997). The product quality itself it is not only one characteristic but a set of characteristics. For what parameters we must submit the guarantee of quality? It might be difficult to decide. Should that be for all the parameters or purposely chosen ones? Monitor of all parameters it would increase the costs so there must be selected only

\footnotetext{
${ }^{1}$ Ph.D., JEP University in Usti nad Labem, Czech Republic, dian@ @fvtm.ujep.cz
} 
the important ones. These important parameters can be divided into two specific groups firstly into measurable critical parameters and secondly into critical defects (attributes) sometimes also called essential characteristics (CSE) or critical to customer (CTQ) characteristics. In order to choose the appropriate parameters it is necessary to consider parameters that must comply with law, norms and standards, and parameters that are the most important for the customer. Some of the customers underline such parameters in own specifications using specific representative marks or implicitly assume safety, regulations and functional parameters having particular $\mathrm{C}_{\mathrm{pk}}$ level. Generally expected level for safety parameters is $C_{\mathrm{pk}}=1,67$, regulation parameters and functional parameters $\mathrm{C}_{\mathrm{pk}}=1,33$ but the actual value depends on carmaker and may a bit differ (DIAN M. 2011). The capability indices $\mathrm{C}_{\mathrm{p}}$ and $\mathrm{C}_{\mathrm{pk}}$ were introduced in order to describe manufacturing process status in terms of observed particular characteristics behavior using only several numbers of dimensionless character. Requiring these numbers by a customer a demand for particular process status is expressed in terms of expected number of non-conformities and process itself being stabilized meaning unchanged within defined time range (CHALOUPKA J. 2008). The process capability study begins a long time before SOP (start of production) within design and prototype stage, following pre-serial production, and continues by initial flow stage and must sustain for the whole period of serial production. The early stages of capability study are integrated into APQP process, and the latest in system of CSE management.

\section{Understanding the capability indices and their context}

Process capability refers to the ability of a process to meet the specifications set by the customer or designer. Variation affects a process and may prevent the process from producing products or services that meet customer expectations. Of course we can encounter certain limitations in process capability. It has been common when the customer may ask for part tolerances being very fine that the machinery is not capable to manufacture to that level of exactness or when the designer intentionally prescribes fine tolerance due to his/her feeling of higher safety. In an assembly process it can be difficult to assemble products that vary from the high side of the specification limits to the low side of the specifications. Manufacturers of products who know the process capability can submit this information to the customer. It can then be used to assist in decisions concerning product or process specifications, appropriate production methods, equipment to be used, and time commitments. In claim management the process capability study may be a crucial decision making factor for acceptation or rejection of claims. During manufacturing process or within supplier's management it certainly can be used for appropriate parameter setting of the machinery. The process 
capability study is helping to determine the product uniformity around the defined target. There has long been a question who should prescribe finer tolerance the designer or technologist? The response is surely the technologist and to persuade the responsible personnel especially in engineering department it is usually very difficult. Unfortunately in real production it is merely the designer who defines the tolerance. It is necessary to take into a consideration the connection between terms of guarantee of quality and $\mathrm{C}_{\mathrm{pk}}$ indices. The quality guarantee of $1 \mathrm{ppm}$ which means $\mathrm{C}_{\mathrm{pk}}=1.67$ is required for critical to customer characteristics. These are the most important product and process measurable parameters. Because of their significance the designer rather prescribes fine tolerance since when production department does not meet these limits there is almost nothing going to happen for the customers having no problems with quality. What will happen when the designer prescribes such a fine tolerance than it is not really necessary and quality assurance department must fulfill customer requirement $C_{p}, C_{p k}$ greater than or equal 1,67 ? In this case the technologist have to select such workers with such qualification, machine, and material, set up process parameters, and chose such a gauge to be able such a fine tolerance meet with huge reserve. In the case we meet all the previously mentioned the production will be expensive. We have set up the dimensions and tolerance limits needlessly fine and then increased the production costs in vain (CHALOUPKA J. 2008, DIAN M. 2011). If this historically prevailing approach when only the designer is in charge of the setting up tolerance limits remains unchanged all the product and process characteristics will be met only on $\mathrm{C}_{\mathrm{p}}, \mathrm{C}_{\mathrm{pk}}=1$. For the quality responsible personnel this philosophy creates a significant problem for the customer requires $\mathrm{C}_{\mathrm{p}}, \mathrm{C}_{\mathrm{pk}} \geq 1,67$ (CHALOUPKA J. 2008, DIAN M. 2011). The whole concept of capability indices stems from Genichi Taguchi philosophy of target oriented quality. It means as further the product is from the target value the more severe is loss. Based on Genichi Taguchi philosophy of "Loss Function" the $\mathrm{C}_{\mathrm{p}}, \mathrm{C}_{\mathrm{pk}}$ indices approach and the SPC technique comes mutually together (DiAN M. 2011, ChaloupKa J. 2008, DiAN M. 2011, Dian M. 2012).Comprehension to loss function philosophy is necessary during machinery design preparation stage when future machine ability/capability is determined with respect to customer specifications. Furthermore, the investment policy must be accompanied with contribution and recommendation of product designer and production engineer as it was mentioned before. The $C_{p}$ and $C_{p k}$ process capability indices are mathematical ratios quantifying the ability of a process to produce products within the specifications. The capability indices compare the spread of the individuals created by the process with the specification limits set by the customer or designer.

$$
C_{p}=\frac{U S L-L S L}{6 s}
$$




$$
C_{P k}=\left\{\frac{U S L-\bar{X}}{3 s} ; \frac{\bar{X}-L S L}{3 s}\right\}=\min
$$

Where $\mathrm{C}_{\mathrm{p}}$ is Capability index defined as the ratio of tolerance (USL - LSL) meaning Upper Specification Limit - Lower Specification Limit) and $6 \mathrm{~s}(\mathrm{~s}=$ standard deviation). The $\mathrm{C}_{\mathrm{pk}}$ is Capability index critical defined as the ratio of USL $-\bar{X}$ and $\bar{X}$ LSL), where $\bar{X}$ is mean value and $3 \mathrm{~s}$. The min (minimum) means that the appropriate value it the lesser from the both calculated values representing worse process behavior. The $C_{p}$ is usually considered as the possibilities of the process while $C_{p k}$ is how we are able to use these possibilities. The $\mathrm{C}_{\mathrm{pk}}$ is considered also as so called term "Quality Guarantee". The real values of USL and LSL will be taken out of the drawing which is the determined and agreed customer specifications. The mentioned parameter "s" in the denominator the standard deviation will be calculated from measurement of at least 30 manufactured pieces taken from a real production line. The prerequisite of capability indices utilization is to perform a normality test or at least histogram in order to decide whether the set of data obtained shows a normal distribution. For the practical Capability study the most important is the $C_{\mathrm{pk}}$ since immediately shows about the current Quality Guarantee. Furthermore, the $\mathrm{C}_{\mathrm{p}}$ displays the quality of pre-production while $\mathrm{C}_{\mathrm{pk}}$ displays the quality of production. The philosophy when some characteristics are within tolerance it is good is not valid anymore. We are not interested in whether the results are only within tolerance range; nowadays it is more important where in the tolerance range the results are located. Particularly speaking whether there is sufficient reserve in side of the tolerance range determining sufficient quality guarantee, and acceptable risk or not. Considering quality spiral it is crucial to start from the beginning that means the marketing department has to agree with customer on critical characteristics and what would be the level of Quality Guarantee in term of $\mathrm{C}_{\mathrm{p}}, \mathrm{C}_{\mathrm{pk}}$ that is usually anchored in document "Quality Targets". The designer than has to consider the fines of the tolerance range. The technologist must the critical characteristics set up wider. The purchasing department may not purchase incapable material/parts, the maintenance department has to set up $\mathrm{C}_{\mathrm{p}}$ and the setter must adjust the $\mathrm{C}_{\mathrm{pk}}$. Finally, the production department must be aware of the philosophy of manufacture in the center of the tolerance (ChaloupKa J. 2008, Dian M. 2011, Dian M. 2012). Concerning the capability indices values interpretation it is desirable the indices being equal and greater than 1 . The value of $\mathrm{C}_{\mathrm{p}}=\mathrm{C}_{\mathrm{pk}}=1$ reflects the process being centered and determines a border between good quality and poor quality as well. The values less than 1 are undesirable reflecting the process inability to meet customer expectations. On the other hand the 
greater this value is the better. The most common required capability indices values are shown in figure 1.
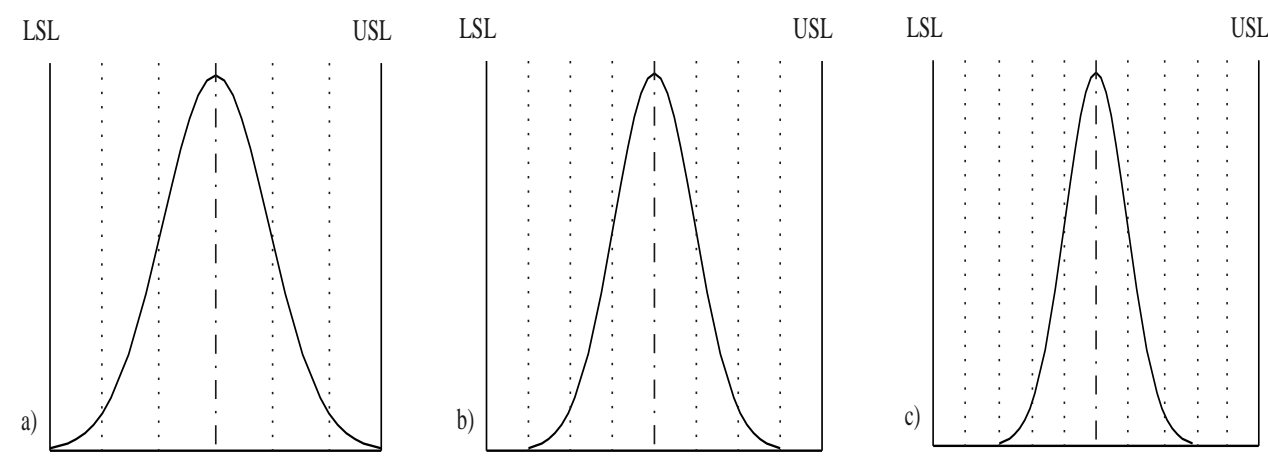

Fig. 1. The level of quality guarantee: a) $\left.\pm 3 s ; C_{p}=C_{p k}=1 ; 2700 \mathrm{ppm}, \mathrm{b}\right) \pm 4 \mathrm{~s} ; C_{p}=C_{p k}=$ $1,33 ; 64 \mathrm{ppm}, \mathrm{c}) \pm 5 \mathrm{~s} ; C_{p}=C_{p k}=1,67 ; 1 \mathrm{ppm}$.

Source: own study

The level of Quality guarantee is represented by free space between the normal curve and specification limit. The description stems from normal distribution uses $\mu$ (population mean) as target value and $\sigma$ (population standard deviation) as quality guarantee level. Due to the fact that we use sampling instead of the whole population we are allow using $\bar{X}$, Median, Modus as population mean, and s (standard deviation) as the variability to describe normal distribution.

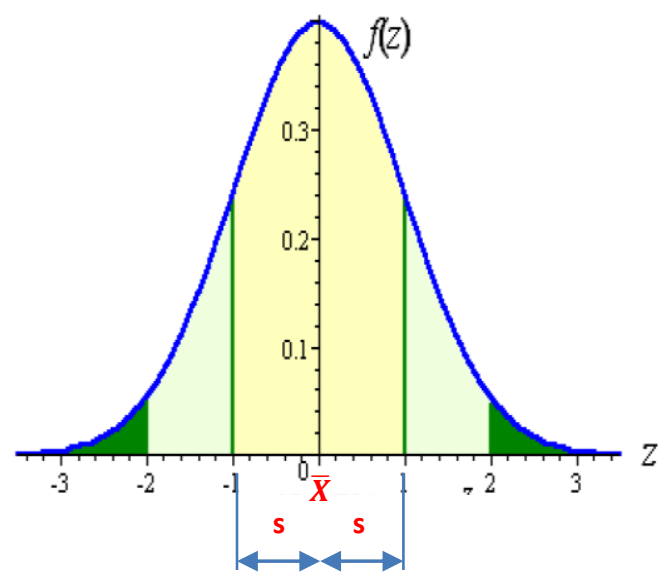

Fig. 2. The Normal (Gauss) distribution.

Source: own study 
Table 1. The relation between Capability indices, Quality guarantee \& Standard deviation

\begin{tabular}{|c|l|c|c|}
\hline Interval & \multicolumn{1}{|c|}{$\begin{array}{c}\text { Estimation in } \\
\text { interval }\end{array}$} & $\begin{array}{c}\text { Estimation out of the interval } \\
\text { (Risk or Quality guarantee } \\
\text { level) }\end{array}$ & $\mathrm{C}_{\mathrm{p}}=\mathrm{C}_{\mathrm{pk}}$ \\
\hline $\bar{X} \pm 1 \mathrm{~s}$ & $68.28 \%$ & $317200 \mathrm{ppm}$ & 0.33 \\
\hline $\bar{X} \pm 2 \mathrm{~s}$ & $95.45 \%$ & $45050 \mathrm{ppm}$ & 0.67 \\
\hline $\bar{X} \pm 3 \mathrm{~s}$ & $99.73 \%$ & $2700 \mathrm{ppm}$ & 1 \\
\hline $\bar{X} \pm 4 \mathrm{~s}$ & $99.9936 \%$ & $64 \mathrm{ppm}$ & 1.33 \\
\hline $\bar{X} \pm 5 \mathrm{~s}$ & $99.9999 \%$ & $1 \mathrm{ppm}$ & 1.67 \\
\hline $\bar{X} \pm 6 \mathrm{~s}$ & $99.9999998 \%$ & $2 \mathrm{ppb}$ & 2 \\
\hline
\end{tabular}

Source: own study

The capability indices show how the real manufacturing process or a manufactured part behave while showing performance that can be described by Normal distribution within specifications limit determined by a customer then. Furthermore, it means fitting into the specification limits with required free space between the normal curve and specification limits. We have been presenting and discussing only the formulas for capability of process/product so far. In a wide context of capability study we ought to introduce two more capability indices. It is necessary to introduce a capability of machinery and gauge capability as well. The significance and relation of all the capability indices is depicted in figure 3.

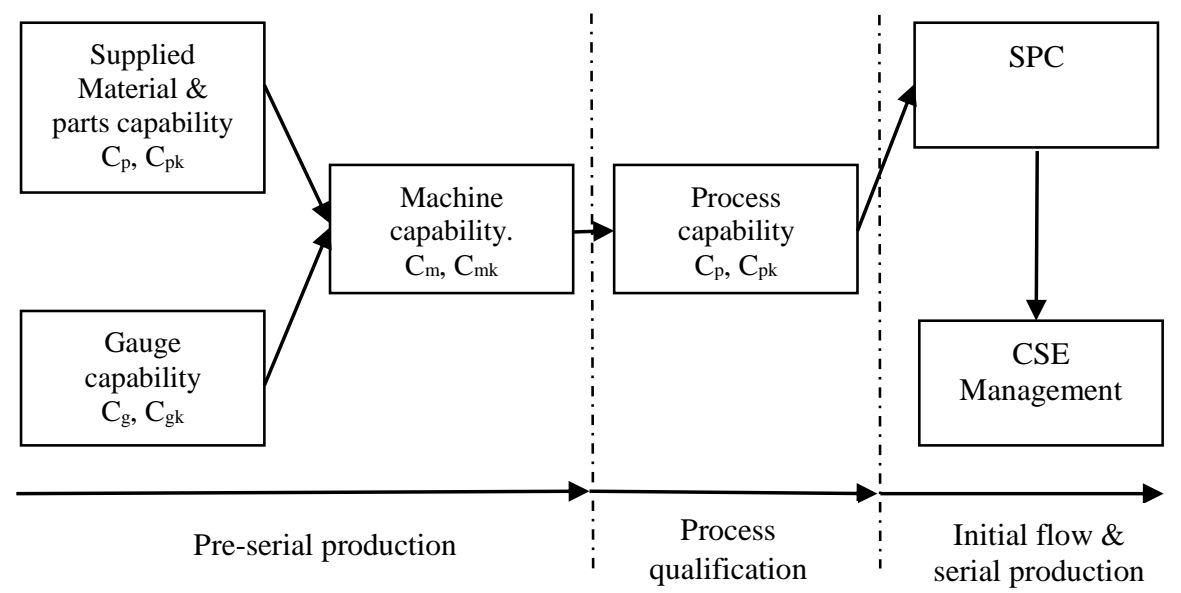

Source: CHALOUPKA J. 2008

Fig. 3. The stages of capability study. 
The capability of machinery can be expressed as following:

$$
\begin{aligned}
& C_{m}=\frac{\frac{3}{4}(U S L-L S L)}{6 s_{M}}=\frac{U S L-L S L}{8 s_{M}} \\
& C_{m k U}=\frac{\frac{3}{4}\left(U S L-\overline{X_{M}}\right)}{3 s_{M}}=\frac{U S L-\overline{X_{M}}}{4 s_{M}} \\
& C_{m k L}=\frac{\frac{3}{4}\left(X_{M}-L S L\right)}{3 s_{M}}=\frac{\overline{X_{M}}-L S L}{4 s_{M}} \\
& C_{m k}=\min \left(C_{m k U} ; C_{m k L}\right)
\end{aligned}
$$

The procedure to determine capability of the machine must follow these four steps:

1. Setting up the particular machine.

2. Measure minimum of 50 manufactured consecutive pieces.

3. Perform normality test or create a histogram.

4. Calculate $\overline{X_{m}}$ (mean value from data obtained) and $s_{m}$ (standard deviation from data obtained).

The capability of gauge stems from Ford (15\% of bandwidth) or Bosch (20\% of bandwidth) methodology and can be expressed as following (FABIAN F., HORÁLEK V., KŘEPELA J., MiChÁLEK J., CHMELíK V., CHODUNSKÝ J., KRÁL J. 2007):

$$
\begin{aligned}
& C_{g}=\frac{0.15(U S L-L S L)}{6 s_{g}} \\
& C_{g k U}=\frac{(T+0,075 \Delta)-\overline{X_{g}}}{3 s_{g}} \\
& C_{g k L}=\frac{\overline{X_{g}}-(T-0,075 \Delta)}{3 s_{g}} \\
& C_{g k}=\min \left(C_{g k U} ; C_{g k L}\right)
\end{aligned}
$$

The procedure to determine capability of the gauge must follow these four steps:

1. Calibrate the gauge.

2. Measure 50 times standard (the same manufactured piece).

3. Perform normality test or create a histogram. 
4. Calculate $\overline{X_{g}}$ (mean value from data obtained) and $s_{g}$ (standard deviation from data obtained).

Where $\mathrm{T}=$ Standard $=$ conventionally true value of standard, $\Delta=$ USL-LSL, $\overline{X_{g}}=$ mean value from data obtained, $s_{g}=$ standard deviation from data obtained.

For the easier practical way we can consider being the machine capability indices $C_{m}, C_{m k}$ higher about 0,33 than required value of $C_{p}$. $C_{p k}$ indices (see table 2).

Table 2. The relationship between $C_{p}, C_{p k}$ and $C_{m}, C_{m k}$ indices

\begin{tabular}{|c|c|}
\hline When: $\mathrm{C}_{\mathrm{p}} \geq \mathrm{C}_{\mathrm{pk}} \geq 1$ & Then: $\mathrm{C}_{\mathrm{m}} \geq \mathrm{C}_{\mathrm{mk}} \geq 1,33$ \\
\hline $\mathrm{C}_{\mathrm{p}} \geq \mathrm{C}_{\mathrm{pk}} \geq 1,33$ & $\mathrm{C}_{\mathrm{m}} \geq \mathrm{C}_{\mathrm{mk}} \geq 1,67$ \\
\hline $\mathrm{C}_{\mathrm{p}} \geq \mathrm{C}_{\mathrm{pk}} \geq 1,67$ & $\mathrm{C}_{\mathrm{m}} \geq \mathrm{C}_{\mathrm{mk}} \geq 2$ \\
\hline
\end{tabular}

Source: CHALOUPKA J. 2008

\subsection{The capability study}

Previously mentioned and depicted in figure 3 the first capabilities are calculated within pre-serial stage of production. The process itself is simultaneously in parallel performed in our own factory as well as in supplier's processes. Within pre-serial manufacturing process it is the APQP (Advanced Product Quality Planning) methodology and PPAP (Production Part Approval Process) requiring the capability study for defined product and process characteristics. The APQP is divided into a couple of stages where it is the „Planning and definition“stage when Capability indices are required to submit in order to get a picture of previous Quality guarantee and information about the quality on similar product and process. In the stage of "Process Design and Development" there has been a requirement for preliminary capabilities study and then in "Product and process validation" stage as well. In this stage there has been a connection to PPAP and measurement system evaluation (APQP 2008, PPAP 2006). Again the preliminary Capability study is focused on characteristics defined by Control plan and submits the information about manufacturing process readiness for production. The measurement equipment for the control of the specified characteristics by a Control plan stemming from technical specification the specified measurement equipment and methods should be used complying with MSA (Measurement System Analysis). During capability evaluation in pre-serial stage there has been used short term capability approach while during initial flow and serial production within CSE management a long term approach is used. The short term approach can be used for example when evaluating the newly made production line during its process acceptance or during evaluation of supplier's 
production line. Furthermore, within preliminary repeated capability analysis the short approach is used as well. On the other hand the long term capability is used for production process evaluation in real serial production conditions or during initial flow stage. It is necessary to add that crucial condition of success is the determination of Capability study conditions between supplier and customer in terms of amount of measured parts, number of subgroups, specifications, methods of statistical regulations, methods of characteristics measurement, sampling, gauge, and finally the process of processing the results. A short term Capability study is shown in table 3.

Table 3. The content and relationship between short and long term capabilities

\begin{tabular}{|c|c|c|}
\hline Short term & Long term (estimation) & Long term (real) \\
\hline $\begin{array}{c}\text { Acceptance of machinery at } \\
\text { contractor premises or } \\
\text { supplier }\end{array}$ & $\begin{array}{c}\text { Simulated serial production } \\
\text { conditions }\end{array}$ & $\begin{array}{c}\text { Real serial production } \\
\text { conditions }\end{array}$ \\
\hline $\begin{array}{c}50 \text { consecutives pieces } \\
\text { (automotive at least } 30 \\
\text { pieces) }\end{array}$ & $\begin{array}{c}25 \text { subgroups with 5 pieces } \\
\text { within same control } \\
\text { intervals }\end{array}$ & $\begin{array}{c}5 \text { subgroups with 5 pieces per } \\
\text { day within same control } \\
\text { intervals for 25 days }\end{array}$ \\
\hline $\begin{array}{c}\text { Results recorded in time } \\
\text { sequence of production }\end{array}$ & $\begin{array}{c}\text { Creation of Shewhart } \\
\text { diagram }\end{array}$ & Usage of Shewhart diagrams \\
\hline $\begin{array}{c}\text { Normality test or histogram } \\
\text { Normality test or } \\
\text { histogram }\end{array}$ & Normality test or histogram \\
\hline Calculate capability indices & Calculate capability indices & Calculate capability indices \\
\hline
\end{tabular}

Source: own study

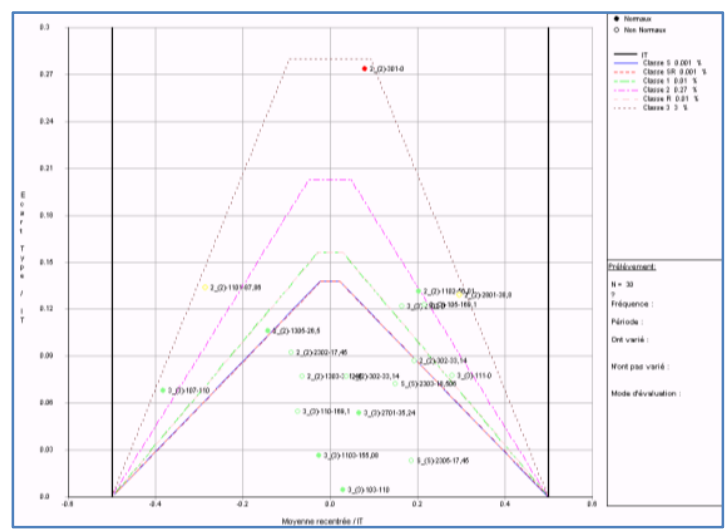

Fig. 4. Preliminary Capability study in pre-serial production.

Source: own study 

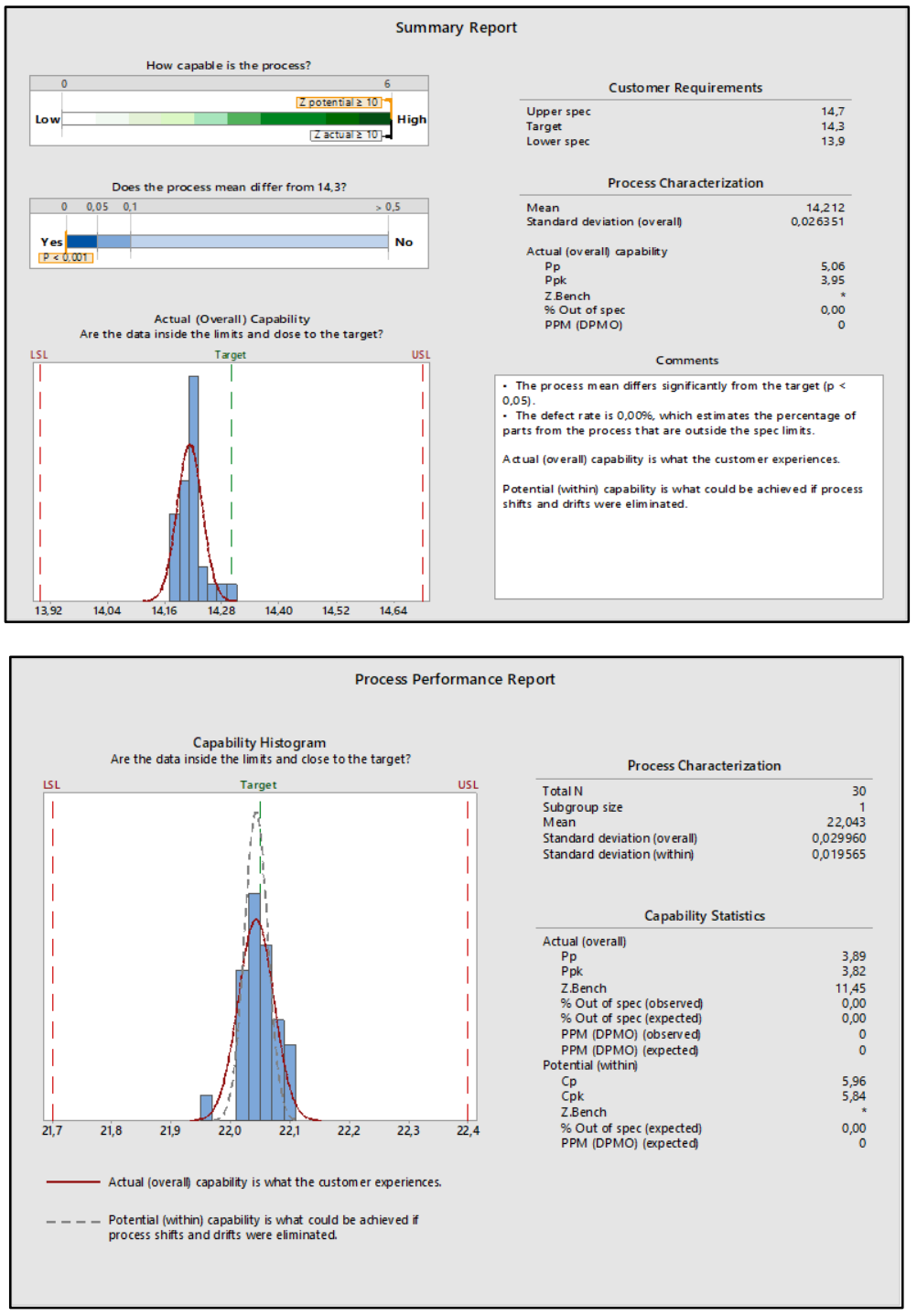

Fig. 5. Example of short term capability for a particular dimension.

Source: own study

In serial production the supplier must guarantee that each delivered part complies with all the required characteristics by the rigorous application of the surveillance plan. The supplier must provide proof thereof via archived measurement. One of the tool available may be CSE Management. In mass production the capability of the supplier`s manufacturing process that allows the CSE to be checked must be regularly checked by the supplier and maintained at agreed level (DIAN M. 2012A, PSA 2006, 
ISO/TS 16949:2009). The implementation of the SPC with regular feedback is necessary must in CSE Management and Capability improvement or sustaining process (DIAN M. 2011, DIAN M. 2012A, PSA 2006). The main philosophy of CSE Management implementation is to prevent the customer off risk links to quality, guarantee the functionalities required by the customer, and ensure the integration of the components chain in the vehicle. The CSE management uses long term capability approach. If there is any slippage of CSE beyond the tolerances the supplier must immediately implement the appropriate containment measures as sorting, individual part inspection etc.

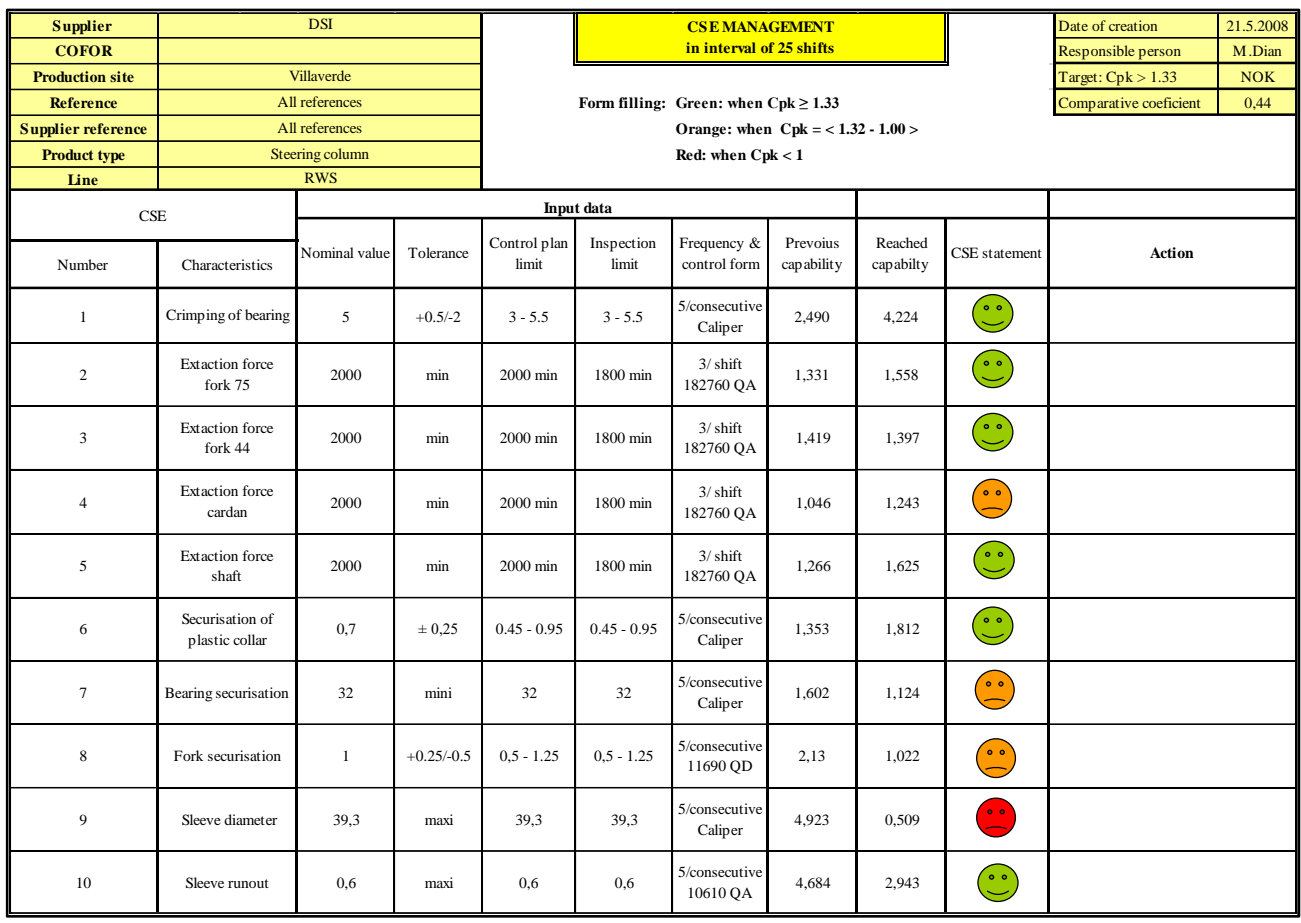

Fig. 6. Example of long term capability report in CSE Management.

Source: own study

\section{Summary}

The international demand for sustainable and continuously improved quality level of manufactured products stemming from customer expectations and besides anchored in ISO/TS 16949:2009 is revealed via capability indices approach. The article reflect the capability approach as an indispensable tool for process and product behavior prediction. The clarification and mutual relationship between particular 
Capability indices, their required limits, theoretical basis, the connection and significance in different steps of pre-serial and serial production have been discussed. Further, there has been stressed the importance of cooperation between designer, technologist, and the quality responsible including machinery preparation stage, customer expectation, and SPC significance as a tool for regulation of quality level and quality guarantee. Moreover, the procedures for Capability indices are described, the short and long term procedure and their proper utilization in order to be used as general methodology for any potential users. Finally, some examples from automotive industry are shown, especially the Capability study in pre-serial stages of production using TAG software with focus on all dimensions, a part of short term Capability focused on CSE/CTQ parameters using MINITAB software, and then after initial flow stage meaning in real serial production the weekly basis report to the customer enabling to monitor actual quality status and fast possible remedy reaction. The article submits comprehension methodology for evaluation and management of process and product quality accompanying with real examples in order to simplify the idea and approach to its smooth utilization.

\section{Bibliography}

1. Ginn D., Streibel B., Vital E.V. 2007. Navrh Six Sigma. CSJ. Praha.

2. SuMmers D. 1997. Quality. Prentice Hall, Inc. New Jersey.

3. DiAn M. 2011. The Role of Statistical Process Control in Quality Assurance within Automotive Industry. In: Quality Production Improvement. Czestochowa, pp. 9-22. ISBN 978-83-934225-3-1.

4. Chaloupka J. 2008. Jednoduse kvalita. Red Cat. Praha.

5. DiAn M. 2011. Nektera rizika soucasne praxe pri zajistovani kvality vyrobku. In: Rizika podnikovych procesu. FVTM UJEP. Usti nad Labem.

6. DIAN M. 2012. Contemporary problems with manufactured product quality and tools for problem solving. X. In: Toyotarity. Materials and Special Purpose Products Quality. University of Maribor.

7. DIAN M. 2012A. The risks connected to quality of supplied parts and their influence on manufactured quality in serial production. In: Rizika podnikovych procesu. FVTM UJEP. Usti nad Labem.

8. Fabian F., Horálek V., KŘepela J., Michálek J., ChMelík V., ChodunskÝ J., KRÁl J. 2007. Statisticke metody rizeni jakosti. CSJ, Praha. ISBN 978-80-02-01897-1.

9. APQP 2008. Advanced Product Quality Planning. CSJ Praha. ISBN 978-80-02-02142-1.

10. PPAP 2006. Production Part Approval Process. CSJ Praha. ISBN 80-02-01833-8.

11. PSA 2006. Supplier Quality Management Principles. PSA France.

12. ISO/TS 16949:2009. Czech Society for Quality (CSJ). Praha. 